\title{
AMBIENTE E QUALIDADE DE VIDA - PERCEPÇÕES DE PARTICIPANTES DO CENTRO DE TRADIÇÕES GAÚCHAS (CTG) NOVA QUERÊNCIA DE BOA VISTA- RORAIMA
}

Silvana Aparecida Mendes Matsdorff ${ }^{1}$, Claudete Rempel ${ }^{2}$, Luís Fernando da Silva Laroque ${ }^{3}$

Resumo: Qualidade de vida é um conceito pessoal e subjetivo. Diz respeito a como a pessoa percebe o mundo e a si própria, tem relação com o bem-estar físico, psicológico e social e também com sua cultura, seus valores, condição econômica, expectativas de vida, relação com o ambiente e políticas públicas. $\mathrm{O}$ estudo objetivou identificar as percepções de participantes de uma rede social denominada Centro de Tradições Gaúchas (CTG) Nova Querência de Boa Vista-RR sobre qualidade de vida e a influência deste ambiente nesse contexto. A pesquisa foi qualitativa, utilizando entrevistas como instrumento de coleta de dados. O estudo foi realizado com administradores, instrutores e participantes das diversas atividades físicas e culturais oferecidas no CTG que participam no mínimo três vezes por mês do Centro. A coleta de dados ocorreu em novembro de 2012 e as entrevistas foram analisadas, utilizando-se a técnica de análise de conteúdo. Constatou-se que o conceito de qualidade de vida é multidimensional e que os participantes da pesquisa consideram que o CTG tem influência positiva em sua qualidade de vida, especialmente no aspecto social que repercute positivamente em seu bem-estar geral.

Palavras-chave: Qualidade de vida. Ambiente. Socialização.

\section{ENVIRONMENT AND QUALITY OF LIFE - THE PERCEPTIONS OF PARTICIPANTS IN “CENTRO DE TRADIÇÕES GAÚCHAS (CTG) NOVA QUERÊNCIA”- LOCATED IN BOA VISTA- RORAIMA}

Abstract: Quality of life is a personal and subjective concept. Regarding how a person perceives the world and himself, it is related to his physical, psychological and social welfare, and also with his culture, values, economical conditions, life expectations, relationship with the environment and public policy. The objective of this study is to identify the perceptions of the participants in a social network called

1 Educadora Física, Pedagoga, Mestre em Ambiente e Desenvolvimento. E-mail. profesilvana@hotmail.com

2 Bióloga, Doutora em Ecologia e Docente do Centro Universitário UNIVATES. E-mail: crempel@univates.br

3 Historiador, Doutor em História e Docente do Centro Universitário UNIVATES. E-mail: 1flaroque@terra.com.br 
"Centro de Tradições Gaúchas (CTG) Nova Querência" located in Boa Vista-RR, about the quality of life and the influence of this environment within that context. The research was qualitative, interviewing administrators, instructors and participants of different physical and cultural activities offered by CTG and who participates at least three times a month. The information collected occurred on November 2012 and the interviews were analyzed using the technique of content analysis. It was found that the concept of quality of life is multidimensional and that the participants consider that the center has a positive influence on his quality of life, especially in the social aspect that reflects positively on his overall welfare.

Keywords: Quality of Life. Environment. Relationships.

\section{INTRODUÇÃO}

Compreendido como um termo polissêmico, resultado de uma construção social, com marcas culturais, a qualidade de vida abrange muitos significados que refletem os valores, experiências e conhecimentos individuais e da coletividade nas diferentes épocas, em diferentes espaços e por meio das diferentes histórias vividas (MINAYO; HARTZ; BUSS, 2000). A Organização Mundial de Saúde (OMS) conceitua qualidade de vida como sendo "a percepção do indivíduo de sua posição na vida no contexto da cultura e sistema de valores nos quais ele vive e em relação aos seus objetivos, expectativas, padrões e preocupações" (WHOQOL GROUP apud FLECK, 2000, p. 34).

O conceito de qualidade de vida é complexo, difere em seu significado dependendo da época, da cultura e do grupo étnico do indivíduo, sendo que o mesmo indivíduo pode percebê-la de maneira diversa em diferentes momentos da vida. Está relacionada com as percepções que cada um tem de si e dos outros, bem como do mundo que o rodeia, podendo ser avaliada por meio de critérios como a educação, a formação de base, a atividade profissional, as realizações pessoais, as competências adquiridas, o otimismo e a saúde (LEAL, 2008).

O panorama mundial modifica-se rapidamente. Concomitantemente com o avanço acelerado da tecnologia e a velocidade da difusão das informações, problemas das mais diversas ordens surgem ou se agravam a cada dia, tornando complexa a vivência humana. Desigualdades sociais, acelerado crescimento demográfico, fome, pobreza, a globalização difundindo e impondo a cultura das grandes potências e influenciando a cultura de povos e países menos desenvolvidos, conflitos gerados pela busca do poder e do capital, são alguns dos exemplos que podem ser citados.

Pode-se afirmar também, que se vive no mundo da produção, da transformação e divulgação do conhecimento, porém, ainda de forma fragmentada. Partindo do princípio que a realidade é complexa e multifacetada, que qualquer acontecimento relativo ao ser humano apresenta diversas dimensões, compreende-se que a análise dessas dimensões deva ser feita de forma integrada, numa perspectiva interdisciplinar, para a compreensão dos fenômenos sociais de uma maneira mais humanizada e totalizante (MINAYO, 1991; VILELA; MENDES, 2003). 
Ao se fazer referência à qualidade de vida, pode-se dizer que se faz referência à saúde individual e coletiva em todos os seus aspectos. "Etimologicamente, o termo saúde, em latim sallus, significa são, inteiro; em grego, o significado é inteiro, real, integridade" (VILELA; MENDES, 2003, p. 528-529). Partindo desse pressuposto, não se poderia conceber a fragmentação da saúde humana em física, social e mental, mas há a necessidade de entendê-la, pesquisá-la e buscar alternativas para sua complexa rede de demandas a partir de uma visão holística interdisciplinar.

$\mathrm{Na}$ área da Saúde Coletiva a interdisciplinaridade coloca-se como exigência interna, uma vez que a saúde e a doença no seu âmbito social envolvem concomitantemente: as relações sociais, as expressões emocionais e afetivas e a biologia, traduzindo, por meio da saúde e da doença, as condições e razões socio-históricas e culturais dos indivíduos e grupos (VILELA; MENDES, 2003).

Apesar de tema complexo, a interdisciplinaridade tem se apresentado como alternativa para a construção do conhecimento, numa perspectiva de diálogo e enriquecimento entre os diversos saberes, de maneira a atender a complexidade e os desafios apresentados pelo mundo atual, dentre eles, os relacionados à saúde e demais problemas socioambientais (GOMES; DESLANDES, 1994; MINAYO, 1994).

Compreendido como um termo polissêmico, resultado de uma construção social, com marcas culturais, a qualidade de vida, segundo Minayo, Hartz e Buss (2000), abrange muitos significados, que refletem os valores, experiências e conhecimentos individuais e da coletividade nas diferentes épocas, em diferentes espaços e por meio das diferentes histórias vividas. Para estes autores, a qualidade de vida é uma noção intrínseca do homem, que tem sido aproximada ao grau de satisfação encontrada na vida familiar, amorosa, social e ambiental e à própria estética existencial. Pressupõe a capacidade de efetuar uma síntese cultural de todos os elementos que determinada sociedade considera seu padrão de conforto e de bem-estar.

$\mathrm{O}$ entendimento sobre o que seja qualidade de vida, portanto, varia de indivíduo para indivíduo, dependendo da sua carga de conhecimento, das relações que cada um estabelece em suas teias de convivência, das políticas públicas, da forma como a sociedade age e se organiza e das expectativas individuais sobre bem-estar (ALMEIDA; GUTIERREZ; MARQUES, 2012).

Os Centros de Tradições Gaúchas (CTGs), criados com o objetivo de recuperar valores rurais do passado, de gaúchos (nascidos no Rio Grande do Sul) são sociedades civis que buscam valorizar, cultuar e divulgar as tradições da cultura gaúcha (OLIVEN, 1991). O primeiro Centro de Tradições Gaúchas, denominado 35 CTG, como referência ao ano em que foi deflagrado o Movimento Farroupilha, foi fundado no dia 24 de abril de 1948, em Porto Alegre (OLIVEN, 1993). Dentre as finalidades do 35 CTG que deu origem aos demais Centros, constava em seus estatutos o zelo pela tradição do Rio Grande do Sul, enfatizando suas histórias, suas lendas, canções e costumes; a divulgação dessas tradições ao restante do Brasil e países vizinhos; a elevação moral e cultural do Rio Grande do Sul e o incentivo à criação de núcleos regionalistas no 
Estado. O desenvolvimento de atividades político-partidárias, de cunho racial ou religioso era claramente descartado das finalidades do Centro (BARBOSA LESSA, apud OLIVEN, 1991).

O surgimento dos demais CTGs no restante do Brasil tem relação direta com o processo migratório de famílias de gaúchos para outros Estados. A migração para outras regiões se deu por vários motivos, dentre eles, o crescimento da economia agrícola no Rio Grande do Sul, especialmente nos anos 70 com o avanço dos latifúndios, da monocultura e o processo de mecanização agrícola, ocasionando o encarecimento e a escassez de terras para a agricultura familiar, obrigando as famílias a buscarem outras alternativas e locais (SOUZA, 2001).

O Centro de Tradições Gaúchas (CTG) Nova Querência, instalado em Boa Vista, capital do Estado de Roraima foi fundado em 1981, conforme registro em sua primeira ata. O Centro busca divulgar as tradições e o folclore da cultura gaúcha, respeitando a forma como essas tradições foram codificadas e registradas por folcloristas reconhecidos pelo movimento. O Centro possui cerca de 400 sócios, dentre eles, sócios fundadores, sócios patrimoniais e sócios transitórios ou contribuintes. Essa rede visa à integração social dos participantes, que no caso de Roraima não se constitui somente de gaúchos, mas de pessoas das mais diversas naturalidades, devido ao multiculturalismo evidente na região.

O contingente populacional do Estado de Roraima constitui-se de 49,3\% de imigrantes, sendo alguns estrangeiros e sua maioria vindos dos mais diversos Estados Brasileiros, dentre os quais, Rio Grande do Sul, Santa Catarina e Paraná (IBGE, 2009). Esses imigrantes sulistas fixaram residência em Roraima desenvolvendo diversas atividades, principalmente as ligadas à agricultura, à indústria madeireira e ao serviço público. Seu principal objetivo era garantir a melhoria da renda familiar, com o intuito de proporcionar uma qualidade de vida adequada a todos os seus integrantes.

Compactuando com a ideia de Marinho (2005), entende-se que o discurso ambiental não representa somente o discurso voltado ao ambiente natural, abarcando também o processo social, por meio do qual ele é construído e transmitido. Bem como com Sachs (2001, p. 75) quando afirma que "[...] desenvolvimento humano [...] supõe a extensão de todos os direitos - inclusive econômicos, sociais e culturais - ao conjunto de cidadãos. [...] o desenvolvimento implica a cidadania universal efetiva [...]. O mesmo autor assevera que "No sentido forte da palavra, o desenvolvimento implica progressos simultâneos, nos âmbitos social, ambiental e econômico [...]” (SACHS, 2003, p. 63).

Partindo do princípio que o indivíduo e o meio ambiente têm ligação intrínseca, esse ambiente, portanto, promove impactos sobre a saúde dos indivíduos e populações, podendo esses impactos ser positivos ou negativos. Além da responsabilidade de nossos líderes em reconhecer que todas as suas ações afetam a sociedade e o ambiente de forma geral (CAPRA, 2006), bem como da sociedade compreender que a saúde da população - a partir do conceito ampliado - e do ambiente é responsabilidade de todos. 
A saúde como conceito ampliado é compreendida como um bem social e como um conceito positivo, que enfatiza os recursos sociais, ambientais e pessoais, bem como as capacidades físicas do indivíduo e comunidade e não somente como a ausência de doença (HEIDMANN et al., 2006). Dentre várias iniciativas importantes e necessárias, avaliar e mudar os modos de vida, de lazer e trabalho é um dos aspectos considerados essenciais.

Para tanto, a implementação de ações que assegurem benefícios para a saúde da população é urgente e necessária, uma vez que tais ações repercutirão tanto no bemestar do indivíduo, quanto das pessoas com as quais ele se relaciona. Sendo assim, tanto o lazer quanto o trabalho e as demais atividades do ser humano, devem ser fontes de saúde. "A saúde é um direito humano fundamental, e a consecução do mais alto nível possível de saúde é a mais importante meta social mundial, cuja realização requer a ação de muitos outros setores sociais e econômicos, além do setor saúde" (BRASIL, 2002, p. 33).

Diante do exposto, este estudo tem como objetivo identificar as percepções de participantes de uma rede social denominada Centro de Tradições Gaúchas (CTG) Nova Querência de Boa Vista-RR sobre qualidade de vida e a influência deste ambiente nesse contexto.

\section{MÉTODOS}

Para identificar as percepções de participantes de uma rede social denominada Centro de Tradições Gaúchas (CTG) Nova Querência de Boa Vista-RR sobre qualidade de vida estabeleceu-se uma pesquisa que, quanto à forma de abordagem do problema foi qualitativa, pois lida com o fenômeno subjetivo, sendo as respostas sobre as percepções dos participantes do CTG acerca do conceito de qualidade de vida e outros aspectos referentes à sua vivência no Centro, analisada sob a ótica do conteúdo, segundo a metodologia proposta por Bardin (2010).

O estudo foi realizado em novembro de 2012, com administradores, instrutores e participantes das diversas atividades físicas e culturais oferecidas no CTG Nova Querência de Boa Vista-RR que frequentavam no mínimo três vezes por mês o Centro, os quais foram convidados e participaram por adesão. Os participantes que aderiram, assinaram o Termo de Consentimento Livre e Esclarecido - TCLE. Foram excluídos os que participavam somente das atividades físicas.

Foram utilizadas como técnicas de pesquisa: entrevista com perguntas semiestruturadas individualmente e grupo focal. Para Lervolino e Pelicioni (2001), o grupo focal pode ser considerado uma entrevista de grupo, porém, por meio de discussões, numa dinâmica de ouvir a opinião do outro e também posicionar-se, não se caracterizando como um processo de alternância entre perguntas e respostas. Consiste na interação entre pesquisador e participantes com o objetivo de colher informações, 
baseadas nas experiências e pontos de vista do colaborador a partir da discussão focada em tópicos específicos relativos à pesquisa.

As entrevistas foram gravadas, transcritas e após, analisadas a partir das questões que compõem a própria entrevista semiestruturada. As entrevistas individuais ocorreram no período de 20 a 28 de novembro de 2012. Os grupos focais foram realizados no período de 14 a 29 de novembro de 2012. Antecipadamente foi contatado o Patrão (administrador geral) do CTG que designou a secretária do Centro para disponibilização de nomes e números de telefones dos administradores, orientadores de atividades físicas e culturais e de pessoas de diferentes grupos e idades que participam com mais assiduidade no Centro, bem como para a organização do espaço onde as reuniões aconteceriam.

Os grupos foram organizados e identificados, para preservação de suas identidades, da seguinte maneira: 1) Participantes da Invernada Artística Juvenil (adolescentes): "A"; 2) Participantes da Invernada Artística Adulta (jovens):“J”; 3) Pais de crianças e jovens que participam de atividades no Centro e que também são frequentadores assíduos: "P"; 4) Frequentadores mais antigos: "MA"; 5) Componentes da Invernada Artística Xirus: "X"; 6) Administradores: "ADM"; 7) Orientadores de atividades físicas e culturais: "OA". Cada entrevistado nos grupos foi identificado também com um número a partir do1 até o número total de participantes. Ex.: A1 - Adolescente 1. J3 - Jovem 3.

Participaram das entrevistas individuais, cinco orientadores de atividades físicas e culturais, que corresponde a $100 \%$ dos orientadores de atividades do Centro e sete membros da equipe administrativa, dos nove convidados. Para os grupos focais, foram convidadas 75 pessoas, sendo que 36 participaram, compondo cinco grupos de diferentes faixas etárias, a partir dos 11 anos de idade, o que correspondeu a $48 \%$ dos convidados.

A pesquisa teve início após autorização pelo Comitê de Ética em Pesquisa da Univates, com o projeto aprovado por meio do parecer no 78067, em 20 de agosto de 2012.

\section{RESULTADOS E DISCUSSÃO}

Por meio das análises realizadas acerca das respostas dos participantes desse estudo, emergiram sete categorias em relação ao que eles consideram como qualidade de vida, conforme se observa na Tabela 1 . As análises se deram pela frequência das respostas apresentadas, sendo que cada participante elencou mais de um aspecto em sua resposta. 
Tabela 1 - Percepção (em percentual - \%) sobre qualidade de vida dos participantes do CTG Nova Querência de Boa Vista - RR

\begin{tabular}{lccccccc}
\hline \multicolumn{1}{c}{ Categoria } & A & J & P & MA & X & ADM & OA \\
\hline Estar na companhia de pessoas amigas & 71 & 86 & 17 & 57 & 100 & 71 & 80 \\
Sentir-se bem nos lugares onde está & 14 & 14 & 67 & 28 & 37 & 28 & 20 \\
Ter saúde & 43 & 71 & 17 & 86 & 50 & 43 & 20 \\
Ser feliz & 28 & 43 & 17 & 43 & 25 & 57 & 40 \\
Ter as necessidades fundamentais & & & & & & & \\
atendidas (educação, segurança, moradia, & - & - & 100 & 71 & - & 57 & 40 \\
emprego etc.) & - & - & & & & & \\
Ter bastante dinheiro & - & - & 83 & 28 & 12 & - & 20 \\
Lazer & - & - & 33 & - & 25 & 14 & 20 \\
\hline
\end{tabular}

Legenda: A- Adolescentes; J- Jovens; P- Pais; MA- Participantes mais antigos; X- Xirus; ADM- Administradores; OA- Orientadores de atividades físicas e culturais

Fonte: Dados da pesquisa (2014)

Observa-se na Tabela 1, que a Categoria "Estar na companhia de pessoas amigas" obteve maior destaque em cinco dos sete grupos entrevistados. O conceito de qualidade de vida associado às boas relações sociais, especialmente às amizades, evidencia-se nos seguintes relatos: "Qualidade de vida é a pessoa viver bem, com quem ela está, ser feliz com os amigos e aproveitar" (A1, 14. Nov. 2012, p. 3); "É a gente se sentir bem onde a gente está, com os amigos [...]" (A6, 14. Nov. 2012, p. 3); "Qualidade de vida é ter um bom convívio com as pessoas à sua volta [...]” (J3, 22. Nov. 2012, p. 2). Outros participantes relataram também:

Qualidade de vida "pra” mim começa por a pessoa ter saúde, um bom ambiente familiar, um bom ciclo de amizade. Ter o suficiente para ter aquelas coisas que a gente gosta de ter ou comprar. Não precisa sobrar nada, mas que também não falte. E a amizade e a satisfação de olhar pra frente e ver que a gente vai deixar alguma coisa boa aqui na Terra (MA4, 28. Nov. 2012, p. 7).

Qualidade de vida é a gente viver no meio de um ambiente que a gente goste, que todos são amigos. Não ter nenhum inimigo. Do menor ao mais idoso, tudo "representa" pra gente. A gente tem esse carinho, esse amor por todos (X4, 29. Nov. 2012, p. 4).

Verifica-se, portanto, que a vivência humana está intimamente ligada à presença, à participação ativa de outros indivíduos. No convívio social, são desenvolvidas as mais diversas formas de relações, proporcionando em muitos casos o apoio social entre os indivíduos, que é caracterizado pelo auxílio oferecido tanto por pessoas quanto por grupos com os quais se tem contato habitualmente. Esse auxílio produz efeitos positivos 
para quem o recebe e para quem o oferece. Trata-se de se perceber valorizado nos grupos dos quais se faz parte, sentindo que nesse grupo existem pessoas com as quais se pode contar nas mais diversas situações, recebendo auxílio sempre que necessário, podendo ser emocional ou afetivo, ou também, se for o caso, auxílio material, dependendo do grau de necessidade (AMENDOLA; OLIVEIRA; ALVARENGA, 2011).

Argyle (1991) destaca a relevância das amizades para o bem-estar do indivíduo e elenca o trabalho, o lazer e os relacionamentos como os três fatores primordiais, responsáveis pela satisfação de uma pessoa com a vida, tendo sido identificado esses três aspectos em diferentes culturas. Ao que tange ao fator relacionamento, a família, o romance e a amizade foram as três formas evidenciadas como mais intimamente relacionadas à felicidade dos indivíduos. Nesse contexto, pesquisas confirmam que "[...] os relacionamentos são mais importantes para o bem-estar subjetivo do que o dinheiro" (VAILLANT, 2003, p. 1380).

A resposta "Ter saúde" apareceu com maior frequência nas narrativas dos Frequentadores Mais Antigos. Já o grupo de Pais destacou primeiramente o "Atendimento às necessidades fundamentais", como o trabalho, a moradia, educação, salário, segurança etc., como principais elementos na definição da qualidade de vida, conforme se verifica nas seguintes afirmativas:

[...] É ser viva, ter saúde. Primeiro é ter saúde, sempre ter saúde. Saúde pra a gente poder fazer o que a gente está fazendo hoje. É poder ver o CTG, é poder comer, é poder beber, é poder se divertir, é poder terminar de criar os nossos filhos e depois os nossos netos [...] (MA6, 28. Nov. 2012, p. 8).

Qualidade de vida em primeiro lugar é ter saúde. Saúde e um bom salário para poder ter essa saúde. Outro "lugar" é a segurança. [...] E é claro que depois vem o lazer, boa remuneração para poder se ter as coisas materiais. E liberdade. Tudo isso somado dá uma liberdade. Qualidade de vida pra mim é isso (P4, 27. Nov. 2012, p. 3).

Primeiro, para ter uma boa qualidade de vida, depende de um bom trabalho, um bom salário. Assim a gente pode sustentar bem a família, dar o conforto. Ter um espaço, uma comunidade onde a gente possa levar os filhos, levar a família, se divertir. Enfim, é poder realmente ter aquilo que a gente quer na vida. Ter o alimento, ter as coisas materiais e ter um ambiente aonde a gente possa encontrar os amigos (P2, 27. Nov. 2012, p. 2).

Qualidade de vida pra mim é ter um lugar seguro para morar, ter as condições para manter uma casa e também ter um lazer, onde você pode ir com a sua família e que nesse lazer você pode ter uma segurança. [...] Então qualidade de vida "pra" mim é um espaço seguro, uma moradia segura e uma situação financeira "mais ou menos" (P1, 27. Nov. 2012, p. 2-3).

Conforme Brigagão (1999), os direitos humanos classificam-se em três gerações, tendo como referência a sua evolução histórica: a primeira delas é a geração dos direitos 
civis e políticos, na qual se encontra o direito à liberdade, à vida e ao voto por exemplo. A segunda diz respeito aos direitos sociais, direitos econômicos e culturais, que são eles: o direito à saúde, educação, trabalho, segurança, moradia, dentre outros. Os direitos: à paz, ao patrimônio comum da humanidade e ao desenvolvimento fazem parte da terceira geração. $\mathrm{O}$ mesmo autor assevera que os direitos sociais, econômicos e culturais são direitos que devem ser garantidos pelo Estado. Para tanto, há a necessidade de uma postura comprometida e de empenho por parte dos governantes para que esses direitos sejam efetivamente desfrutados por todos os cidadãos.

Com exceção de um participante da pesquisa, os demais foram unânimes em afirmar que o CTG Nova Querência influencia positivamente em sua qualidade de vida. Justificativas como o fato de poder encontrar com amigos e pessoas em quem se pode confiar, a importância da integração social, a possibilidade de participar em atividades de lazer e descontração e o fato de o ambiente proporcionar felicidade, segurança e bem-estar, foram elementos que se sobressaíram, como é possível observar nos seguintes relatos dos participantes, ao serem questionados se o CTG influencia em sua qualidade de vida: "Acho que sim, porque aqui no CTG a minha vida muda. Fica mais divertido. Eu tenho prazer de estar aqui" (A6, 14. Nov. 2012, p. 3). Outros participantes relataram:

A minha participação no CTG influencia na minha vida, de modo que digamos que, faz bem para mim, para o meu interior, para a minha vida, pro meu coração, "pra" mim. Pelo fato de eu vir aqui, rever meus amigos, ver, conversar, sair entre amigos, dançar, ter um contato (J6, 22. Nov. 2012, p. 2).

Influencia muito. Até no trabalho, porque quando a gente está cansado do trabalho, quer um lugar para o lazer, para descansar, para distrair. Vou onde? Para o CTG. Em casa, quando estou cansado da rotina, com a família, quero fazer alguma coisa diferente, penso, aonde eu vou? Vou para o CTG. Então, aqui é onde eu me divirto. Jogo meu futebol, jogo meu baralho... Então, influencia muito (P2, 27. Nov. 2012, p. 4).

[...] Eu sempre fui apegado a esse clube. Eu deixava de ir em clubes "normais" na cidade para frequentar esse clube. Porque é um clube que você tem uma certa tranquilidade, você conhece as pessoas do teu círculo de amizades, até de negócios. Então, de certa maneira ele contribuiu realmente. Até de uma certa "porcentagem" grande, porque é o clube que você participa a vida inteira. A gente gastou, 10, 15, 20, 30 anos frequentando esse clube e convivendo com pessoas. Então, essas pessoas também influenciaram na vida da gente de uma maneira ou de outra (MA1, 28. Nov. 2012, p. 8).

[...] Como eu disse, "pra" mim, o mais importante aqui é ter uns amigos "pra" trocar ideias, "pra" conversar, "pra" se atualizar. Então, ele tem tido influências. Porque a vida é efêmera e quem fica 25 anos frequentando sempre o mesmo lugar, é porque tem importância sim e tem, porque senão não teria sentido de nós estarmos sempre aqui (MA2, 28. Nov. 2012, p. 8-9). 
Verifica-se nessas narrativas, que as pessoas fizeram uma avaliação de suas vidas no contexto de determinado ambiente, nesse caso o CTG. Nessa avaliação pode ser observado o seu bem-estar subjetivo. Para Campbell (1976), o bem-estar subjetivo pode ser considerado como uma experiência interna, própria de cada indivíduo. Ademais, além da conexão que se faz com a felicidade, estado de espírito, afeto positivo e satisfação, o construto do bem-estar subjetivo também está relacionado à avaliação subjetiva da qualidade de vida (NOGUEIRA, 2001; ALBUQUERQUE; TRÓCCOLI, 2004).

Foi elencado como um dos principais fatores que influenciam na qualidade de vida dos pesquisados, o fato de no Centro, eles poderem vivenciar momentos de integração social, principalmente com pessoas amigas. Sousa e Cerqueira-Santos (2011, p. 63), fazem uma comparação das relações familiares com as relações de amizade. Eles afirmam: "Amigos criam relações com grande probabilidade de serem mais recíprocas, imparciais e menos estressantes. Amigos oferecem companhia, oportunidades para o riso, para o partilhar de atividades [...]".

Como, de modo geral os amigos provêm do mesmo grupo, há um enriquecimento das relações visto que ocorre um compartilhar de histórias, da cultura, de brincadeiras e canções que fizeram parte das experiências vividas e que se tornaram favoritas, bem como das vivências e aprendizados sociais (BEE, 1997). Nesse sentido, considerase sobremaneira a importância das relações de amizade para o bem viver e para o aperfeiçoamento da qualidade de vida.

\section{CONSIDERAÇÕES FINAIS}

As percepções sobre qualidade de vida são multidimensionais e diferem de pessoa para pessoa. Porém, viver de maneira plena, sentindo-se bem em seu ambiente físico e social, estando satisfeito consigo e com suas conquistas pessoais, tendo saúde e acesso aos bens e serviços indispensáveis para a vida é um anseio e uma tarefa complexa para o ser humano.

Constatou-se nesse estudo, que os participantes do CTG Nova Querência de Boa Vista, apesar de terem opiniões diferentes entre si sobre o que seja qualidade de vida, na sua maioria, consideram que ter uma qualidade de vida positiva significa ter saúde, estar feliz, ter segurança, ter à disposição bens e serviços para atendimento das necessidades básicas como: alimentação, educação, serviço de saúde, de infraestrutura, entre outros, mas principalmente, consideram que ter qualidade de vida significa poder desfrutar da companhia de outras pessoas, ter amigos, enfim, relacionar-se socialmente.

Consideram também que aquele ambiente influencia positivamente em sua qualidade de vida de maneira geral, tanto em sua saúde física e emocional, quanto repercutindo nas relações familiares e sociais. O sentimento de pertencimento e de apego àquele ambiente foi mencionado por vários participantes do estudo, que o compararam com sua própria casa, seu lar. Relataram que se sentem seguros e acolhidos 
no CTG, sentem-se pertencentes a um grupo social, que de modo geral lhes apoia, fazendo parte de sua vida, de seu cotidiano e que consideram o CTG Nova Querência como seu lugar favorito.

Considera-se, portanto, que as vivências sociais, em ambiente que ofereça acolhimento, atividades físicas e culturais, como o CTG, e os sentimentos oriundos dessas experiências são elementos que podem proporcionar uma vida mais significativa, com saúde e bem-estar, permitindo que os indivíduos sejam mais felizes, realizados e produtivos, fazendo com que esses sentimentos repercutam positivamente em todos os seus ambientes de convivência. Há que se considerar nesse contexto, a necessidade do empenho e da vontade política e social em se organizar ambientes nos quais as pessoas possam se encontrar, vivenciar o lazer, a arte, o esporte e compartilhar saberes, cultura, sonhos e esperanças, visando à promoção de uma sociedade melhor.

\section{REFERÊNCIAS}

ALBUQUERQUE, A. S.; TRÓCCOLI, B. T.. Desenvolvimento de Uma Escala de BemEstar Subjetivo. Psicologia: Teoria e Pesquisa. v. 20 n. 2, p. 153-164, 2004. Disponível em:<http://www.scielo.br/pdf/ptp/v20n2/a08v20n2.pdf> Acesso em: 16 abr. 2013.

ALMEIDA, M. A. B. de; GUTIERREZ, G. L.; MARQUES, R. Qualidade de vida: definição, conceitos e interfaces com outras áreas, de pesquisa, São Paulo. 1. ed: Escola de Artes, Ciências e Humanidades- EACH/USP, 142p, 2012. Disponível em: 〈http:/www.each. usp.br/edicoes-each/qualidade_vida.pdf $>$. Acesso em: 15 set. 2015.

AMENDOLA, F.; OLIVEIRA, M. A. de C.; ALVARENGA, M. R. M.. Influência do apoio social na qualidade de vida do cuidador familiar de pessoas com dependência. Ver. Esc.

Enf. USP, São Paulo, v. 45, n. 4, Agosto 2011 . Disponível em:<http://www.scielo.br/scielo. php?script=sci_arttext\&pid=S0080-62342011000400013\&lng=en\&nrm=iso>. Acesso em: 16 abr. 2015.

ARGYLE, M.; MARTIN, M. The psychological causes of Happiness. In. STRACK, F.; ARGYLE, M.; SCHWARZ, N. (edited by). Subjective Well-Being: An Interdisciplinary Perspective. Oxford u.a. : Pergamon Press, 1st ed. v. 21, 1991. Disponível em: <http://opus. bibliothek.uni-wuerzburg.de/volltexte/2007/2170/pdf/subjwellbeing.pdf >. Acesso em: 02 dez. 2015.

BARDIN, L. Análise de Conteúdo. São Paulo: Edições 70, 2011.

BEE, H. O ciclo vital. Porto Alegre: Artmed, 1997.

BRASIL. Ministério da Saúde. Secretaria de Políticas de Saúde. Projeto Promoção da Saúde. As Cartas da Promoção da Saúde / Ministério da Saúde, Secretaria de Políticas de Saúde, Projeto Promoção da Saúde. - Brasília: Ministério da Saúde, 2002.

BRIGAGÃO, C.; RODRIGUES, G. Globalização a olho nu. São Paulo: Moderna, 1998.

CAMPBELL, A. Subjective measures of well-being. American Psichologist, v. 31, n. 2, p. 117-124, 1976. 
CAPRA, F. A teia da vida: uma nova compreensão científica dos sistemas vivos. São Paulo: Cultrix, 2006.

FLECK, M. P. de A. O instrumento de avaliação de qualidade de vida da Organização Mundial da Saúde (WHOQOL-100): características e perspectivas. Revista Ciência e Saúde Coletiva [online], v. 5, n. 1, p. 33-38, 2000. Disponível em <http://www.scielo.br/pdf/csc/ v5n1/7077.pdf> Acesso em: 14 abr. 2015.

GOMES, R.; DESLANDES, S. F. Interdisciplinaridade na saúde pública: um campo em construção. Revista Latino-americana. Enfermagem, Ribeirão Preto, v. 2, n. 2, p. 103-114, jul. 1994 . Disponível em: <http://www.scielo.br/pdf/rlae/v2n2/v2n2a08.pdf >. Acesso em 28 mai. 2015.

HEIDMANN, I. T. S. B.et al. Promoção à saúde: trajetória histórica de suas concepções. Texto contexto - enferm. [online], v.15, n.2, p. 352-358. 2006. Disponível em: <http://www. scielo.br/scielo.php?pid=S0104-07072006000200021\&script=sci_arttext $>$. Acesso em: 06 jun. 2015 .

IBGE - Diretoria de Pesquisas, Coordenação de Trabalho e Rendimento, Pesquisa Nacional por Amostra de Domicílio, 2009.

LEAL, C. M. S. Reavaliar o conceito de qualidade de vida. Universidade dos Açores. 2008. Disponível em: <http://www.porto.ucp.pt/lusobrasileiro/actas/Carla\%20Leal.pdf>Acesso em: 30 mai. 2015.

LERVOLINO, S. A ; PELICIONI, M. C. F. A utilização do grupo focal como metodologia qualitativa na promoção da saúde. Rev. Esc. Enf. USP, v.35, n.2, p. 115-121, jun. 2001. Disponível em: <http://www.scielo.br/pdf/reeusp/v35n2/v35n2a03.pdf> Acesso em: 15 mai. 2015.

MARINHO, A. Atividade na Natureza, Lazer e Educação Ambiental: Refletindo sobre algumas possibilidades. Motrivivência, Revista de Educação Física, Esporte e Lazer. 2005. Disponível em:<http://journal.ufsc.br/index.php/motrivivencia/article/view/1184/1919>Acesso em: 9 out. 2015.

MINAYO, M. C. de S. Interdisciplinaridade: uma questão que atravessa o saber, o poder e o mundo vivido. Medicina, Ribeirão Preto, v. 24, n. 2, p. 70-77, abr./jun., 1991. Disponível em: $<$ http://projetos.unioeste.br/pos/media/Intedisciplinaridade_uma_questao_que.pdf $>$. Acesso em: 06 jan. 2015.

MINAYO, M. C. de S. Interdisciplinaridade: Funcionalidade ou utopia? Saúde e Sociedade, v.3, n.2, p.42-64. 1994. Disponível em: <http://www.scielo.br/pdf/sausoc/v3n2/04.pdf>. Acesso em 28 mai. 2014.

MINAYO, M. de S.; HARTZ, Z. M. de A.; BUSS, P. M.. Qualidade de vida e saúde: um debate necessário. Ciência e Saúde Coletiva, v.5, n.1, p. 7-18. 2000. Disponível em: <http:// www.scielo.br/pdf/csc/v5n1/7075.pdf>. Acesso em: 24 abr. 2015.

NOGUEIRA, E. J. Rede de relações sociais: um estudo transversal com homens e mulheres pertencentes a três grupos etários. 2001. 117f. Tese (Doutorado em Educação) - Faculdade de Educação UNICAMP. Campinas/SP, Agosto, 2001. Disponível em:<http://www. 
bibliotecadigital.unicamp.br/document/?code=vtls000235568\&fd=y>.Acesso em: $03 \mathrm{dez}$. 2015.

OLIVEN, R. G. Em busca do tempo perdido: o movimento tradicionalista gaúcho. Revista Brasileira de Ciências Sociais, v. 6, n. 15, 1991.

OLIVEN, R. G. A dupla desterritorialização da cultura gaúcha. In. FONSECA, C. (org.) Fronteiras da cultura: horizontes e territórios da antropologia na América Latina. Porto Alegre: UFRGS, 1993, p. 24-40.

SACHS, I. Brasil rural: da redescoberta à invenção. Estudos avançados [online], v. 15, n. 43, p. 75-82, 2001. Disponível em: <http://www.scielo.br/pdf/ea/v15n43/v15n43a08.pdf> Acesso em: 28 jun. 2015.

SACHS, I. Inclusão social pelo trabalho. Desenvolvimento humano, trabalho decente e o futuro dos empreendedores de pequeno porte no Brasil. Rio de Janeiro: Garamond, 2003.

SOUSA, D. A.; CERQUEIRA-SANTOS, E. C. Redes sociais e Relacionamentos de amizade ao longo do ciclo vital. Rev. Psicopedagogia, v. 28, n. 85, p. 53-66, 2011. Disponível em: <http://pepsic.bvsalud.org/pdf/psicoped/v28n85/06.pdf> Acesso em: 16 abr. 2015.

SOUZA, C. M. de. Gaúchos em Roraima. Porto Alegre: EDIPUCRS, 2001.

VAILLANT, G. E. Mental Health.Am J Psychiatry, v.160, n. 8, p. 1373-1384 August. 2003. Disponível em:<http://ajp.psychiatryonline.org/data/Journals/AJP/3751/1373.pdf>. Acesso em: 02 dez. 2015.

VILELA, E. M.; MENDES, I. J. M. Interdisciplinaridade e saúde: estudo bibliográfico. Revista Latino-americana Enfermagem, v.11, n.4, p. 525-531, jul./ago. 2003. Disponível em: <http://www.scielo.br/pdf/rlae/v11n4/v11n4a16.pdf>. Acesso em: 05 out. 2015. 